\title{
Mortality among children under five years admitted for routine care of severe acute malnutrition: a prospective cohort study from Kampala, Uganda
}

Damalie Nalwanga ${ }^{1 *}$ (D), Victor Musiime ${ }^{1,2}$, Samuel Kizito ${ }^{3}$, John Baptist Kiggundu ${ }^{3}$, Anthony Batte ${ }^{1}$ Philippa Musoke ${ }^{1}$ and James K. Tumwine ${ }^{1}$

\begin{abstract}
Background: Mortality among children under 5 years of age admitted to malnutrition units in sub-Saharan Africa remains high. The burden of HIV infection, a major risk factor for mortality among patients with severe acute malnutrition (SAM), has reduced due to concerted prevention and treatment strategies. None the less, anecdotal reports from the malnutrition unit at Uganda's National Referral Hospital (NRH) indicate that there is high mortality among patients with severe acute malnutrition (SAM) in routine care. Uganda has recently adopted the revised World Health Organization (WHO) treatment guidelines for SAM to improve outcomes. The mortality among children with SAM in routine care has not been recently elucidated. We report the magnitude and factors associated with mortality among children under 5 years of age admitted to the NRH for routine care of SAM.

Methods: This was a cohort study of all severely malnourished children admitted to the NRH between June and October 2017. The primary outcome was two-week mortality. Mortality was calculated using simple proportions and Cox regression analysis was used to determine factors associated with time to mortality. Data was entered into Epidata and analysed using Stata v14.

Results: Two-hundred-sixty (98.5\%) children: 59.6\% male; mean age 14.4 (SD 9.4) months, completed two weeks of follow-up. Of these, $25.2 \%$ (95\% Cl 19.9-30.4\%) died. In-hospital mortality was 20.7\% (95\% Cl15.9-25.6\%). The prevalence of HIV infection was 12.2\%. Factors associated with mortality included: positive HIV status (AHR 2.2, (95\% $\mathrm{Cl} ; 1.2-4.2), p=0.014)$, bacteraemia (AHR 9 (95\% Cl 3.4-23.0), $p<0.001$, and low glomerular filtration rate (eGFR), AHR 3.2; $(95 \% \mathrm{Cl} 1.7-6.3), p=0.001)$.

Conclusions: A 25\% mortality among children with severe malnutrition remains unacceptably high despite significant reduction in HIV prevalence. Children with SAM who are HIV infected, have eGFR below $60 \mathrm{~mL} / \mathrm{min} /$ $1.73 \mathrm{~m}^{2}$ or have bacteraemia, are more likely to die. Further studies to explore the relationship between eGFR and mortality among children with SAM are needed. Studies to establish efficacious antibiotics are urgently required to inform treatment guidelines for children with SAM.
\end{abstract}

Keywords: Severe acute malnutrition, Mortality, Children, Uganda

\footnotetext{
* Correspondence: damalielwanga@gmail.com

'Department of Paediatrics and Child Health, School of Medicine, College of Health Sciences, Makerere University, P. O. Box 7072, Kampala, Uganda

Full list of author information is available at the end of the article
}

(c) The Author(s). 2020 Open Access This article is licensed under a Creative Commons Attribution 4.0 International License, which permits use, sharing, adaptation, distribution and reproduction in any medium or format, as long as you give appropriate credit to the original author(s) and the source, provide a link to the Creative Commons licence, and indicate if changes were made. The images or other third party material in this article are included in the article's Creative Commons licence, unless indicated otherwise in a credit line to the material. If material is not included in the article's Creative Commons licence and your intended use is not permitted by statutory regulation or exceeds the permitted use, you will need to obtain permission directly from the copyright holder. To view a copy of this licence, visit http://creativecommons.org/licenses/by/4.0/. The Creative Commons Public Domain Dedication waiver (http://creativecommons.org/publicdomain/zero/1.0/) applies to the data made available in this article, unless otherwise stated in a credit line to the data. 


\section{Background}

Severe acute malnutrition (SAM) adversely affects the lives of children under 5 years of age in low-income countries. Increasingly malnutrition is recognized as one of the leading contributors to the burden of disease in these countries $[1,2]$. Over 20 million children under the age of 5 years are affected by SAM with an estimated annual mortality of 1-2 million in sub-Saharan Africa alone [3]. In Uganda, $4 \%$ of children under the age of 5 years are wasted, and $1 \%$ of these are severely wasted [4]. In 2006, $7 \%$ of children under 5 years of age admitted at the Acute Care Unit (ACU), Mulago hospital (the national referral hospital in Uganda) had SAM. These children experienced a $24 \%$ mortality, with the majority of deaths occurring in the first week of admission [5].

Recent publications from the MNU at Mulago Hospital indicate that mortality among children admitted for SAM ranges from 9.8 to 25\% [5]. These numbers are dependent on whether children were enrolled in a clinical trial, were relatively stable or were under routine care $[6,7]$.

Mortality among SAM patients under routine care in Mulago Hospital was last assessed objectively in 2006 [5]. The WHO guidelines for inpatient management of children with SAM were revised in 2013 and have contributed to significant reduction in mortality in treatment centres across sub-Saharan Africa [8]. Despite adopting these guidelines, anecdotal reports suggest that Mulago Hospital continues to register high mortality among these children. HIV infection is associated with increased mortality among children with SAM $[9,10]$. In Uganda, children with SAM are routinely screened for HIV, and access to lifesaving antiretroviral therapy (ART) is now widely available. Although ART improves outcomes among children with SAM [9], mortality among children in routine care at Mulago Hospital in the ART era has not been evaluated. Other factors known to be associated with mortality in children with SAM include excess or unnecessary blood transfusion, and co-morbidities including diarrhoea, pneumonia, hypoglycaemia and bacteraemia $[5,7,9,11,12]$. The mortality of children with SAM admitted to MNU for routine care has not been clearly documented, and the factors associated with these mortalities have not been recently evaluated. Hence we report mortality and its associated factors in children under 5 years of age admitted to Mulago hospital for routine care of SAM.

\section{Methods}

\section{Study setting}

The study was conducted at the emergency ward/ acute care unit (ACU) and MNU at Mulago National Referral Hospital. The hospital receives patients from urban and peri-urban areas of Kampala and neighbouring districts as well as those further away referred for further management. The SAM patients are often critically ill, requiring emergency resuscitation at the ACU and $24 \mathrm{~h}$ of observation before transfer to the MNU for treatment and nutritional rehabilitation. Patients in the study received routine standard care for SAM as per the WHO guidelines at ACU and MNU by the clinical team. This includes treatment and prevention of hypoglycemia, hypothermia, dehydration, electrolyte imbalance, treatment of infection with antibiotics (1st line Ampicillin and Gentamycin and second line ceftriaxone unless otherwise indicated at clinicians' discretion), correction of micronutrients with multivitamins and minerals, feeding (F75 and transitioned to ready to use therapeutic feed (RUTF) when they were clinically stable and passed an appetite test) and sensory stimulation. Children less than 6 months received F75 in addition to breast milk during admission and were discharged on breast milk and formula feeds where feasible. A diagnosis of dehydration was made by clinicians based on local guidelines [13]. All clinical and laboratory procedures were done within a $1 \mathrm{~km}$ radius of the Mulago Hospital complex.

\section{Study design}

This was a prospective cohort study of 270 children under 5 years of age with SAM admitted to Mulago National Referral Hospital in Kampala, Uganda between June and October 2017. All children less than 5 years of age with very low weight for height (below $-3 \mathrm{Z}$ scores of the median WHO growth standards [14]), visible severe wasting (mid upper arm circumference (MUAC) < $11.5 \mathrm{~cm}$ ) or nutritional oedema, and whose caregivers gave written informed consent were enrolled consecutively.

\section{Study procedure}

The study team included two pre-trained research assistants (a nurse and a medical officer) and the first author. Children admitted to the ACU with SAM within the previous $24 \mathrm{~h}$ were assessed for eligibility. They were assessed for danger signs such as altered level of consciousness, convulsions, dehydration, hypothermia or hyperthermia. Children with danger signs were resuscitated appropriately. The weight, height/length, weight for height/length, MUAC and presence of oedema were then re-checked to ensure the child met the criteria for the diagnosis of severe malnutrition. Informed consent was obtained from the parent or primary caregiver of the child who met the study criteria. A structured questionnaire was administered to the caregivers to obtain the child's history.

Blood samples from all the eligible children were obtained at enrolment for complete blood count (CBC), serum electrolytes, urea, creatinine, liver enzyme tests, 
blood culture, malaria blood slide, random blood sugar (RBS) and HIV serology or DNA PCR (for infants < 18 months of age whose mothers tested positive on HIV serology). The blood samples were delivered to the laboratory within $2 \mathrm{~h}$ of collection. Estimated glomerular filtration rate (eGFR) was calculated using Schwartz formula [15]. The results of laboratory investigations were captured in the questionnaire and a copy was provided to the clinical team caring for the patients. Each participant had a chest X-ray done within 3 days of admission, which was read by two radiologists. The two radiologists discussed, agreed, and produced one report. If they did not agree, a third radiologist acted as a tie breaker. The $\mathrm{CBC}$, serum electrolytes and malaria slide were done in the Mulago Hospital central laboratory, which is a WHO 3-star laboratory. Blood cultures were done using the BACTEC culture system, in the Makerere University College of Health Sciences Medical Microbiology laboratory, which is certified by the College of American Pathologists (CAP). The rapid HIV serology tests were done in the MNU ward side laboratory. Blood samples for HIV DNA-PCR tests were sent to Baylor Uganda, Centre of Excellence (COE)/Mulago Paediatric Infectious Diseases Clinic (PIDC).

The participants were followed-up for 2 weeks. The two-week period was chosen because previous studies among children with SAM have demonstrated that $75 \%$ of deaths occur in the first week and up to $90 \%$ by end of the second week [5]. Follow-up data was captured in the participant questionnaire. Participants were censored if they survived until day 14 of follow up or earlier if they were lost to follow up.

\section{Data management}

The questionnaires were completed by study staff and reviewed weekly for accuracy and completeness prior to data entry. Data was entered into an electronic database using Epidata version 3.1 software package with built-in quality control checks. The data was double-entered and validated by two entrants. The final data was backed up and exported to Stata version 14.1 (STATA CORP, TEXAS USA) for analysis. Continuous variables were summarized using means and standard deviations for normally distributed data. Categorical variables were summarized using frequencies, and percentages. Mortality proportion and rate were determined. Time to mortality was also determined. We performed Cox regression analysis to determine factors associated with time-to-mortality. Bivariate analysis was performed for each of the independent variables to determine whether they were independently associated with mortality. The strength of the association was assessed using hazard ratios (HR) and 95\% confidence intervals. Multivariate analysis was performed to determine whether the independent variables were jointly associated with the outcome. Variables with a $p$-value of $\leq 0.2$ at bivariate analysis were considered for the multivariate model. The variables were entered into a stepwise model. Interaction between the variables which remained in the model was assessed using the Chunk test. This was followed by assessing for confounding using a difference of $\geq 10 \%$ between the crude and adjusted measure of effect (HR) for the variables that would have gone out at each step. Significance was set at $p$ value of 0.05 or less. A Kaplan Meier curve was drawn and the differences between groups were determined using the Log rank test.

\section{Results}

Participant clinical and demographic characteristics

A total of 270 children below 5 years of age with SAM were recruited, as shown in Fig. 1. The mean age was 14.4 months (SD9.4) and 161/270 (59.6\%) were male. Thirty-three (12.2\%) children were under 6 months of age and 229 (85.9\%) were under 24 months. Most of the 270 caregivers were the participants' mothers (78.5\%) with a mean age of 27.4 years (SD8.3) and $11.3 \%$ below 19 years of age. Many of them (36.6\%) were housewives and the majority $(57.8 \%)$ had attained primary level education.

The majority (90\%) of the participants had a recent history of weight loss, cough (191/270; 70.7\%), diarrhoea $(151 / 270 ; 55.9 \%)$ and fever $(142 / 270 ; 52.6 \%)$ prior to hospitalization. Thirty-four (12.6\%) had chronic medical illnesses, including congenital heart diseases and cerebral palsy. Forty-one (15.2\%) of participants had documented evidence of having received medication for their current presentation prior to admission. Visible wasting, pallor, dermatosis and dehydration were observed in many of the participants. One-hundred and twenty-three (45.6\%) of the participants had oedematous SAM. Nine (3.4\%) participants had hypothermia. Seven participants were admitted in shock (Table 1). Overall, 33 (12.2\%) children were HIV-infected; 16 (48.5\%) of these were identified prior to enrolment while 17 were diagnosed during the study. Of the HIV-infected children identified prior to enrolment, $10(62.5 \%)$ were receiving anti-retroviral therapy (ART). Mean duration of ART was 8 days (SD 9.7). The total number of HIV-exposed infants (infected and uninfected) was 40/189 (21.2\%); of these, 22 (55\%) were HIV-exposed but uninfected (HEU). The prevalence of HIV in the oedematous children was $11 / 123$ (8.9\%) compared to22/147 (15\%) in the non-oedematous group, $p=0.132$.

Ten (3.7\%) of the participants had hypoglycaemia in the first $24 \mathrm{~h}$ of admission. Mean total white cell count was $14.1 \times 10^{3} \pm 7.4$ cells $/ \mu \mathrm{L}$, with mean differential neutrophil and lymphocyte count of 40.5 and $49.1 \%$ respectively. Thirty-six percent of the participants had severe 


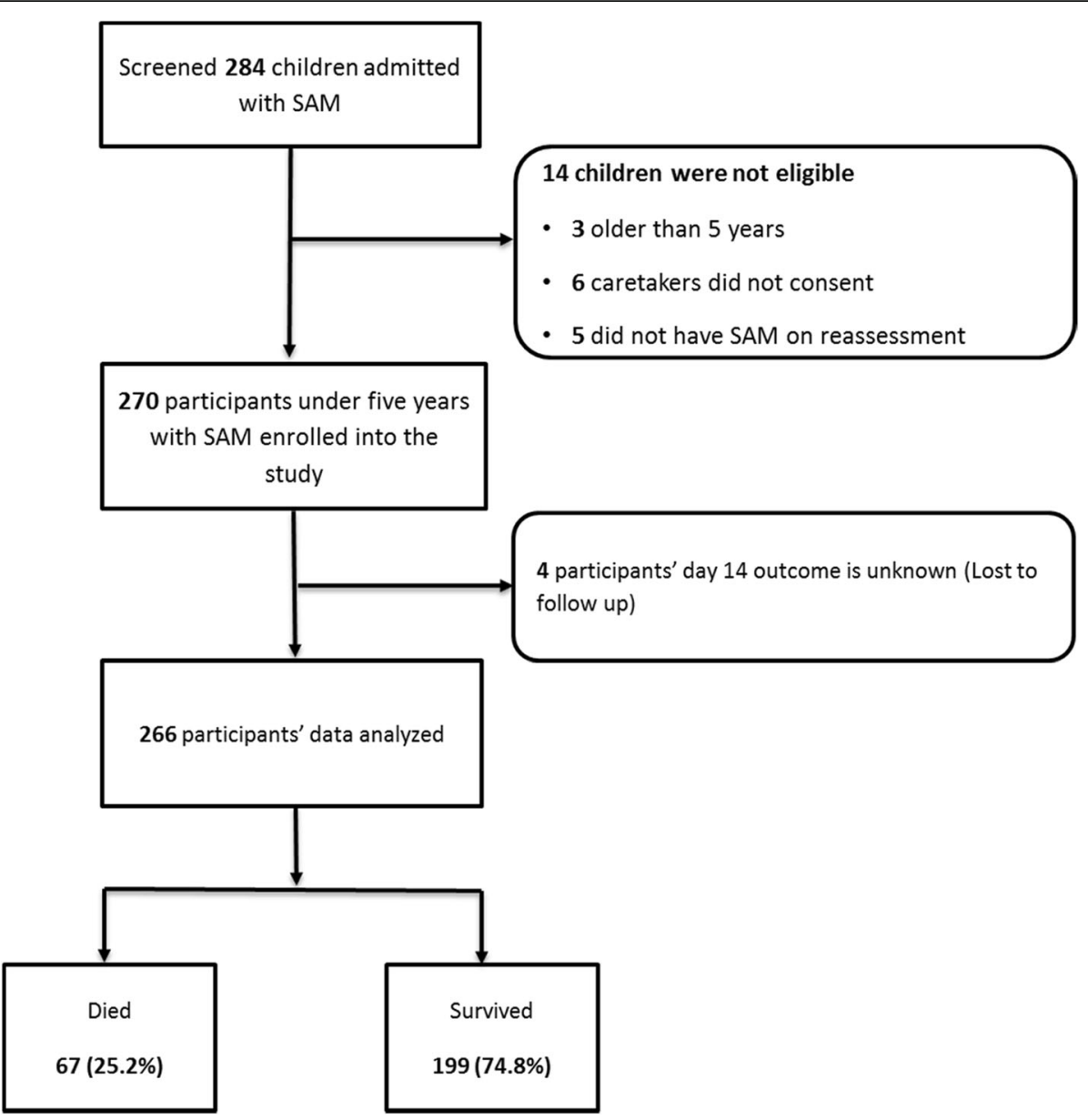

Fig. 1 Study profile for recruitment of 270 children admitted for routine care of SAM

anaemia (haemoglobin $<7 \mathrm{mg} / \mathrm{dL}$ ) while 9 (3.3\%) had anaemia requiring blood transfusion (haemoglobin $<4$ $\mathrm{mg} / \mathrm{dL})$. Eight (3\%) of the 270 blood cultures had bacterial growth. The isolated organisms included E.coli (2), Candida species (1), Salmonella spp (1), Streptococcus pneumoniae (2), Citrobacter freundii (1), and Rhodococcus Spp (1). Five of the 7 bacterial isolates were resistant to ampicillin, 1 to gentamicin and 4 to ceftriaxone. None was resistant to both ampicillin and gentamycin. Of the 183 patients that had chest X-rays, 76 (41.5\%) had abnormal results (Table 2).

\section{Mortality among the participants}

The overall mortality of the children in the study was 67/266 (25.2\%; 95\% CI 19.9-30.4\%). The overall mortality rate was 2.4 deaths per 100 person days of follow-up. In-hospital mortality was 56/270 (20.7\%) during the 14 days of follow-up (Table 3). Eight (11.9\%) participants died in the ACU, 44 (65.7\%) died in MNU, 4 (6\%) died on general paediatric wards, and 11 (16.4\%) died at home following discharge against medical advice. No participants died during transfer to MNU. Twenty
(29.85\%) of the mortalities occurred within $48 \mathrm{~h}$ of admission, $27(40.30 \%)$ within 3-7 days of admission and $20(29.85 \%)$ between 8 and 14 days of admission. Thirtyfour $(60.7 \%)$ of the participants died during day shifts while $22(39.2 \%)$ died at night i.e. 8 am and $8 \mathrm{pm}$. The most common diagnoses around the time of death were shock (20.9\%), acute watery diarrhoea (13.4\%), aspiration pneumonia or bronchopneumonia (11.9\%), and pulmonary TB (9\%). Of the $147 \mathrm{HIV}$-unexposed infants, 35 (23.8\%) died, compared to 8 of the $22(36.4 \%)$ in HEU group, $p=0.21$.

The participants' survival time was 11.7 days (11.312.4) on average. The Kaplan Meier survival curve for children with and without HIV is shown in Fig. 2. The survival time was significantly lower among the HIVpositive participants (10.6, CI; 8.9-12.2 days) compared to their HIV-negative counterparts $(11.9, \mathrm{CI} ; 11.3-12.4$ days) with a $p$ value of 0.008 .

Significant factors associated with survival time at multivariate analysis included; positive HIV status (AHR 2.2, 95\% CI; 1.2-4.2, $p=0.014)$, positive blood culture (AHR 9; 95\% CI 3.4-23, $\mathrm{p}=<0.001$ ), and low estimated 
Table 1 History and clinical examination findings of children with severe acute malnutrition admitted to Mulago hospital at enrolment

\begin{tabular}{|c|c|c|}
\hline Variable & $\mathrm{n} / \mathrm{N}$ & Percentage \\
\hline Weight loss & 243 & 90 \\
\hline Cough & 191 & 70.7 \\
\hline Diarrhea & 151 & 55.9 \\
\hline Fever & 142 & 52.6 \\
\hline Appetite loss & 133 & 49.3 \\
\hline Vomiting & 127 & 47 \\
\hline Skin rash & 64 & 23.7 \\
\hline Convulsions & 26 & 9.6 \\
\hline Loss of consciousness & 5 & 1.9 \\
\hline Difficulty in breathing & 47 & 17.4 \\
\hline Abdominal pain & 57 & 21.1 \\
\hline \multicolumn{3}{|l|}{ Medical history } \\
\hline Chronic illness excluding $\mathrm{HIV}^{5}$ & 34 & 12.6 \\
\hline Received treatment prior to admission & 41 & 15.2 \\
\hline \multicolumn{3}{|l|}{ Temperature $\left({ }^{\circ} \mathrm{C}\right): \mathrm{N}=263$} \\
\hline Normal (35-37.4) & 177 & 67.3 \\
\hline Hypothermia $\left(<35^{\circ} \mathrm{C}\right)$ & 9 & 3.4 \\
\hline Hyperthermia $\left(\geq 37.5^{\circ} \mathrm{C}\right)$ & 77 & 29.3 \\
\hline \multicolumn{3}{|l|}{$\operatorname{MUAC}^{\mathrm{a}}(\mathrm{cm}): N=237$} \\
\hline Less than 11.5 & 138 & 58.2 \\
\hline 11.5 and above & 99 & 41.8 \\
\hline \multicolumn{3}{|l|}{ Weight for Height/ Length (Z score) } \\
\hline$\leq-3$ & 210 & 77.8 \\
\hline$>-3$ & 60 & 22.2 \\
\hline Signs of Vitamin A deficiency & 5 & 1.9 \\
\hline \multicolumn{3}{|l|}{ Grade of edema $^{b}$} \\
\hline Grade I & 22 & 17.9 \\
\hline Grade II & 45 & 36.6 \\
\hline Grade III & 56 & 45.5 \\
\hline Shock & 7 & 2.6 \\
\hline Dehydration & 98 & 36.3 \\
\hline Visible wasting & 212 & 78.5 \\
\hline Dermatosis & 119 & 44.1 \\
\hline Thrush & 61 & 22.6 \\
\hline Pallor (palmar and/or conjunctiva) & 143 & 53 \\
\hline Jaundice & 7 & 2.6 \\
\hline Signs of Respiratory Distress & 48 & 17.8 \\
\hline Abnormal breath sounds ${ }^{c}$ & 44 & 16.4 \\
\hline Abnormal heart sounds ${ }^{d}$ & 7 & 2.6 \\
\hline Abnormal motor findings & 21 & 7.8 \\
\hline Abdominal Distension & 57 & 21.1 \\
\hline
\end{tabular}

Chronic illness include congenital heart defects, cerebral palsy, epilepsy, and hernia, $N=270$, unless otherwise stated due to missing data, ${ }^{a} M U A C$ Mid Upper Arm Circumference, ${ }^{b} N=123$ (nuber of children with oedema) ${ }^{c}$ Abnormal breath sounds: rhonchi, crepitations; ${ }^{d}$ Abnormal heart sounds: murmurs glomerular filtration rate (eGFR), (AHR 3.2; 95\% CI 1.76.3, $p=0.001$ ), as summarised in Table 4 .

\section{Discussion}

This study investigated mortality and associated factors among 270 children under five years of age admitted to Mulago Hospital for care of severe acute malnutrition (SAM). The main findings were an overall mortality of $25 \%$ which is higher among children with HIV infection, positive blood cultures and low estimated GFR. Age, diarrhoea, hypoglycaemia, hypothermia, electrolyte imbalance, pneumonia and oral thrush were not associated with mortality in this cohort of children with SAM.

This mortality is similar to the $24 \%$ recorded by Bachou et al. over ten years earlier among patients receiving the standard of care at Mulago hospital [5]. However, the mortality recorded in this study is much higher than that reported by more recent studies conducted in selected populations: $14 \%$ in 2017 and 9.8\% in 2018 by Rytter et al. and Nabukeera et al. respectively $[6,7]$. Our observational study included all severely malnourished children receiving routine care. Nabukeera et al.'s study was a nested randomised control study (RCT) including a selected population with frequent patient monitoring and access to more resources. Rytter et al.'s study was an observational study but excluded critically ill children.

The mortality in our study is higher than that recorded in retrospective studies from South Sudan (9.3\%) and the Democratic Republic of Congo (DRC)(7.5\%) $[16,17]$. A prospective study in Malawi reported a comparable mortality of $18 \%$ [18]. The higher mortality in our population could be explained by the fact that our study was done in a tertiary referral hospital. In addition, we followed up patients discharged against medical advice. The higher HIV prevalence in Uganda compared to South Sudan and DRC could also explain the difference. Patients in tertiary hospitals are often the most severely ill patients following referral from smaller centres. Eleven of the study participants died at home following discharge against medical advice; which likely contributed to the high mortality. This finding is not surprising considering that a number of children in Uganda and Malawi are documented to die at home following official medical discharge [10, 19].

Mortality among children with SAM in Mulago is still significantly higher than the set targets of 5 and 10\% by the WHO and Sphere standards, respectively, yet the findings in RCTs suggest the mortality can significantly be improved. Most of the deaths, 42 (67\%) in this study occurred in the first week of admission, which is consistent with other observational studies in the same population and sub-Saharan Africa [5, 6, 20, 21]. Closer patient 
Table 2 Assessment findings of children with severe acute malnutrition admitted to Mulago hospital

\begin{tabular}{|c|c|c|}
\hline Variable & $\mathrm{n} / \mathrm{N}$ & Percentage \\
\hline \multicolumn{3}{|c|}{ Glucose levels (mmol/l): $\boldsymbol{N}=268$} \\
\hline$<3$ & 10 & 3.7 \\
\hline $3-<8.3$ & 215 & 80.2 \\
\hline$\geq 8.3$ & 43 & 16.1 \\
\hline \multicolumn{3}{|c|}{ Hemoglobin levels (g/dl): $\boldsymbol{N}=266$} \\
\hline$<7$ & 36 & 13.4 \\
\hline 7.0-9.9 & 132 & 49.5 \\
\hline $10-10.9$ & 46 & 17.2 \\
\hline$>11$ & 52 & 19.9 \\
\hline \multicolumn{3}{|l|}{ Total WBC: $\boldsymbol{N}=266$} \\
\hline Abnormal & 144 & 54.1 \\
\hline \multicolumn{3}{|l|}{ Neutrophils: $\boldsymbol{N}=266$} \\
\hline Abnormal & 135 & 50.8 \\
\hline \multicolumn{3}{|l|}{ Albumin $(\mathrm{g} / \mathrm{l}): \boldsymbol{N}=266$} \\
\hline$<3.5$ & 80 & 30.1 \\
\hline \multicolumn{3}{|l|}{ Total protein (g/l): $\boldsymbol{N}=250$} \\
\hline$<63$ & 207 & 82.8 \\
\hline \multicolumn{3}{|l|}{$\operatorname{ALT}(U / L): N=266$} \\
\hline Elevated & 99 & 37.2 \\
\hline \multicolumn{3}{|l|}{ ALP (U/L): $\boldsymbol{N}=259$} \\
\hline Elevated & 222 & 85.7 \\
\hline \multicolumn{3}{|c|}{$\mathrm{GFR}^{\mathrm{b}} \mathrm{c}\left(\mathrm{mL} / \mathrm{min} / 1.73 \mathrm{~m}^{2}\right): \boldsymbol{N}=261$} \\
\hline$<30$ & 16 & 6.1 \\
\hline $30-<60$ & 46 & 17.6 \\
\hline $60-<90$ & 55 & 21.1 \\
\hline$\geq 90$ & 144 & 55.2 \\
\hline \multicolumn{3}{|l|}{ Sodium (mmol/dl): $\boldsymbol{N}=266$} \\
\hline$<135$ & 77 & 29 \\
\hline \multicolumn{3}{|c|}{ Potassium (mmol/dl): $\boldsymbol{N}=266$} \\
\hline$<3.5$ & 66 & 24.9 \\
\hline \multicolumn{3}{|c|}{ Calcium (mmol/dl): $\boldsymbol{N}=265$} \\
\hline$<2.2$ & 226 & 85.3 \\
\hline \multicolumn{3}{|c|}{ Phosphate $(\mathrm{mmol} / \mathrm{dl}): \mathbf{N}=260$} \\
\hline$<1.28$ & 108 & 42 \\
\hline \multicolumn{3}{|l|}{ Blood smear for Malaria } \\
\hline Positive & 15 & 5.6 \\
\hline \multicolumn{3}{|l|}{ Blood culture } \\
\hline Positive blood culture & 8 & 3 \\
\hline \multicolumn{3}{|l|}{ Chest x-ray: $(N=183)$} \\
\hline Abnormal ${ }^{a}$ & 76 & 41.5 \\
\hline Infiltrates & 61 & 80.3 \\
\hline Consolidation & 15 & 19.7 \\
\hline Hyperinflation & 10 & 13.2 \\
\hline
\end{tabular}

Table 2 Assessment findings of children with severe acute malnutrition admitted to Mulago hospital (Continued)

\begin{tabular}{lll}
\hline Variable & $\mathrm{n} / \mathrm{N}$ & Percentage \\
\hline HIV status & & \\
Total HIV positive & 33 & 12.2 \\
HIV exposed: $N=189$ & 40 & 21.2 \\
HIV exposed -infected & 18 & 45 \\
HIV exposed -Uninfected & 22 & 55 \\
\hline
\end{tabular}

$N=270$, unless otherwise stated due to missing data, ${ }^{2}$ Some participants had more than one abnormality, ${ }^{b} \mathrm{GFR}$ (Using Schwatz formula) $=\left(\mathrm{K}^{\mathrm{C}}\right.$ height) $/ \mathrm{cr}$ (mg/dl), (http://nephron.com/bedside_peds_nic.cgi)

monitoring in the first week of admission could bring us closer to these targets.

HIV-positive children had a significantly shorter survival time than HIV-negative children. These findings are similar to the systematic review done by Fergusson et al., and observational studies in Uganda and Malawi $[6,9,10,22-24]$. A significant number of HIV-positive children in this study were diagnosed prior to admission. However, our findings are different from those of Nabukeera et al. where the mortality was lower among HIVpositive children on ART [6].

Children in the ART group in this study tended to have a higher mortality when compared to the ART naive group. This finding could be attributed to the Immune Reconstitution Inflammatory syndrome (IRIS) which occurs in the early days of ART initiation since the mean duration on ART in this group was 8 (SD 9.7) days. Alternatively, these children may have been more severely ill prior to admission, resulting in investigation for HIV and initiation of ART, compared to the ART naïve children who had not yet been identified. In this study, there was no difference in mortality among the HIV exposed infected (HEI) and HIV exposed uninfected (HEU) infants, possibly due to the small numbers. Similarly there was no difference between the HIV unexposed uninfected (HUU) and the HEU. On the other hand, a study in Uganda comparing morbidity between HEU and HUU children showed a higher risk of SAM among the HEU group, partially attributed to early breastfeeding cessation [25]. Despite the reduction in prevalence of HIV among children with SAM from 40 to $50 \%$ in $2006-2009[5,11]$, to less than $15 \%$ in $2016-$ $2018[6,7]$ and $12.2 \%$ in this study, mortality from SAM has remains high and HIV has remained an important contributor to these deaths. Prevention of HIV, early initiation of ART, nutritional support for HIV-positive children, and close monitoring of HIV-positive children on ART to prevent malnutrition and its complications could help reduce severe malnutrition, which is associated with poor outcomes.

A positive blood culture was associated with a significantly reduced survival time among these children. 
Table 3 Mortality among children with severe acute malnutrition admitted to Mulago hospital

\begin{tabular}{|c|c|c|c|}
\hline Variable & Dead n/N $N^{a}$ & $\%(95 \% \mathrm{Cl})$ & $P$ value \\
\hline \multicolumn{4}{|l|}{ Age (months) } \\
\hline$<6$ & $8 / 32$ & $25(0.1-0.4)$ & \multirow[t]{3}{*}{0.990} \\
\hline $6-23$ & $50 / 197$ & $25.4(0.2-0.3)$ & \\
\hline$\geq 24$ & $9 / 37$ & $24.3(0.1-0.4)$ & \\
\hline \multicolumn{4}{|l|}{ HIV status } \\
\hline Positive & $15 / 32$ & $46.9(28.6-65.2)$ & \multirow[t]{2}{*}{0.003} \\
\hline Negative & $42 / 234$ & $22.2(16.9-27.6)$ & \\
\hline \multicolumn{4}{|l|}{ HIV status awareness at admission } \\
\hline Positive and aware at admission & $10 / 15$ & $66.7(6.3-60.4)$ & \multirow[t]{2}{*}{0.035} \\
\hline Positive and not aware & $5 / 17$ & $29.4(5.3-53.6)$ & \\
\hline \multicolumn{4}{|l|}{ ART status at admission } \\
\hline On ART & $7 / 10$ & $70(4.6-64.6)$ & \multirow[t]{2}{*}{0.077} \\
\hline Not on ART & $8 / 22$ & $36.4(14.5-58.2)$ & \\
\hline \multicolumn{4}{|l|}{ HIV exposure } \\
\hline \multicolumn{4}{|l|}{ HEl and HIV negative } \\
\hline $\mathrm{HEl}$ & $9 / 17$ & $47.1(23.5-72)$ & \multirow[t]{2}{*}{0.004} \\
\hline HIV negative & $52 / 234$ & $22.2(17.3-28)$ & \\
\hline \multicolumn{4}{|l|}{$\mathrm{HEU}^{c}$ and HIV negative } \\
\hline HEU & $8 / 22$ & $36.4(40.5-81.8)$ & \multirow[t]{2}{*}{0.094} \\
\hline HIV negative & $44 / 212$ & $20.8(15.7-26.8)$ & \\
\hline \multicolumn{4}{|l|}{ Edematous } \\
\hline Edematous & $23 / 122$ & $18.9(11.8-25.9)$ & \multirow[t]{2}{*}{0.028} \\
\hline None & $44 / 144$ & $30.6(22.9-38.2)$ & \\
\hline \multicolumn{4}{|l|}{ Diarrhea } \\
\hline Yes & $24 / 116$ & $28.7(64-78.7)$ & \multirow[t]{2}{*}{0.137} \\
\hline No & $43 / 150$ & $20.7(13.2-28.1)$ & \\
\hline \multicolumn{4}{|l|}{ Hemoglobin levels (g/dl) } \\
\hline$<7$ & $12 / 36$ & $33.3(17.2-49.5)$ & \multirow[t]{2}{*}{0.25} \\
\hline$\geq 7$ & $55 / 226$ & $24.3(18.7-30)$ & \\
\hline \multicolumn{4}{|l|}{ Hemoglobin levels (g/dl) } \\
\hline$<4$ & $6 / 9$ & $66.7(28.2-71.7)$ & \multirow[t]{2}{*}{0.004} \\
\hline$\geq 4$ & $61 / 253$ & $24(18.8-29.4)$ & \\
\hline
\end{tabular}

${ }^{a} \mathrm{~N}=$ Number of participants in each category whose outcome was known, ${ }^{\mathrm{b}}$ One of the HIV positive patients was lost to follow up, ${ }^{\mathrm{c}}$ One of the HEU children was lost to follow up

Children with SAM are expected to have severe infections due to the immune suppression caused by malnutrition [26]. Although the prevalence of bacteraemia in this study was lower than that reported in other studies [11, 27-29], it still significantly influenced mortality among children with SAM. Only $15 \%$ of the participants in this study reported receiving treatment prior to admission. Only those with written evidence of previous treatment were included in this category. We, however, suspect that more children received antibiotics prior to admission as Mulago hospital is a tertiary centre where difficult cases from other centres are referred after failing to respond to treatment. Such treatment regularly includes antibiotics, but this is often not documented. Furthermore, use of non-prescription antibiotics is a common practice in low-income countries like Uganda and contributes to antibiotic resistance [30]. This might explain the low prevalence of bacteraemia and might also suggest that the patients who had bacteraemia most likely had overwhelming sepsis or were colonised by bacteria strains that were resistant to the antibiotics they had received. Such children are therefore more likely to die compared to those who might have been infected with susceptible bacteria. Contrary to other studies in 


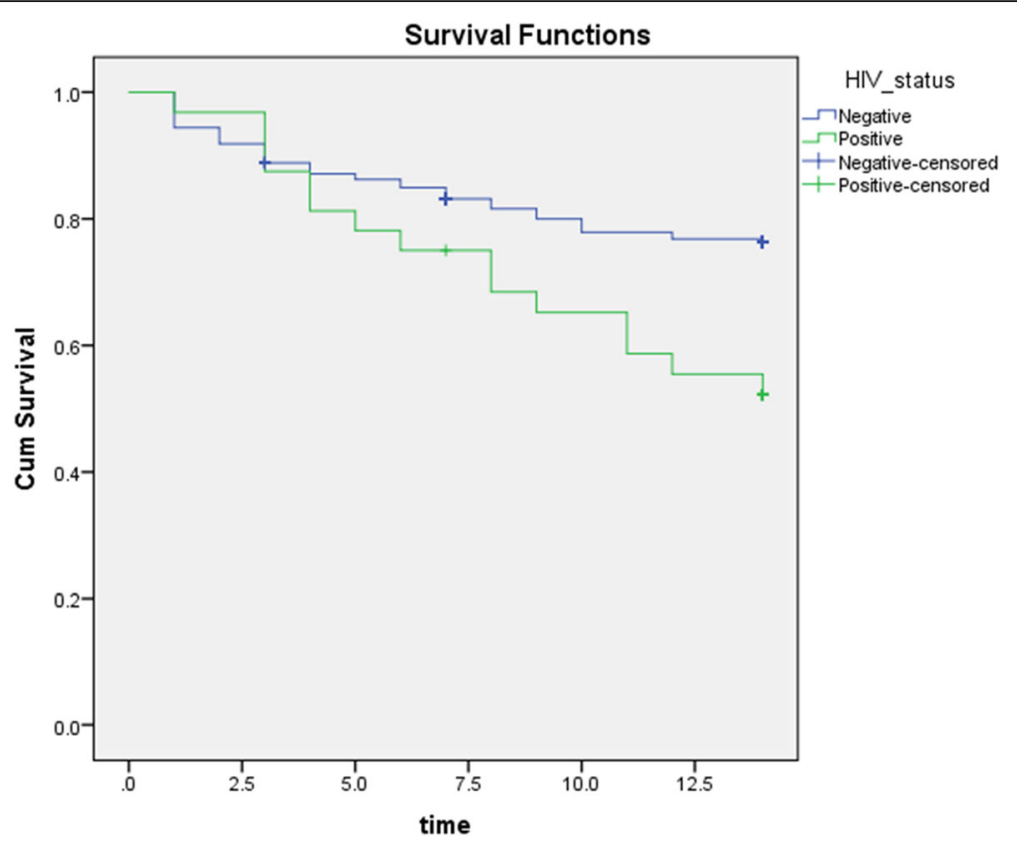

Fig. 2 Kaplan Meier survival curve for children admitted with SAM and HIV positive versus HIV negative

which the most frequently isolated organism was Staphylococcus aureus, the isolated organisms in this study were, Escherichia coli, Streptococcus pneumoniae, Candida species, Salmonella species, Citrobacter freundii, and Rhodococcus species [27, 29]. Resistance to WHOrecommended ampicillin was very high (71.4\%), a finding that is consistent with other studies of SAM children in Africa [11, 27-29, 31]. Resistance to ceftriaxone was also high (57.1\%). This calls for further evaluation of the optimal antibiotics for use among children with SAM.

The survival time of children with a low eGFR below $60 \mathrm{~mL} / \mathrm{min} / 1.73 \mathrm{~m}^{2}$ was 3.2 times less than that of those with eGFR more than $60 \mathrm{~mL} / \mathrm{min} / 1.73 \mathrm{~m}^{2}$. There is a paucity of data on the relationship between poor kidney function and survival among children with malnutrition. However, studies have demonstrated that kidney injury is a risk factor for mortality in children who are critically ill and those with malaria [32, 33]. In our study, even after controlling for factors that indicate compromised perfusion (dehydration, shock, diarrhoea), reduced eGFR remained an independent predictor of reduced survival time. A study of 32 malnourished Jamaican children reported reduced eGFR, which normalised as they recovered from malnutrition. Only a single serum creatinine test at admission was done in our e study, therefore we cannot ascertain whether children developed acute kidney injury or had pre-existing chronic kidney disease. However, acute kidney injury in these children may result from hypovolemia following diarrhoea and vomiting, sepsis, renal toxic medications such as gentamicin, or non-steroidal anti-inflammatory agents.. The relationship between malnutrition and reduced eGFR and its impact on mortality among children with SAM needs to be explored further as it may have significant implications on the management of these children.

Other factors associated with mortality in previous studies including diarrhoea, hypoglycaemia, hypothermia, electrolyte derangements, pneumonia and oral thrush among others were not significant in this study. This may be attributed to the difference in severity of these factors among the participants in this study compared to other studies. Some factors including hypothermia and hypoglycaemia occurred infrequently in this study, $(9 / 263,3.4 \%)$ and $(10 / 269,3.7 \%)$ respectively and may not have reached significance as a result. The correlation between HIV and diarrhoea resulting in interaction may explain why diarrhoea was not significant in this study.

The strengths of the study include: the prospective cohort study design, which is ideal for establishing temporal relationship between mortality and associated factors. The study investigated factors associated with time to mortality which not only guides clinicians on which patients need close follow-up but also helps identify those whose interventions are time-sensitive. The sample size was sufficient to answer the study questions, and participants who left the hospital against medical advice were followed up, thus significantly reducing the rate of loss-to-follow-up. The main limitations include: the results cannot be generalized to all centres in Uganda since the study participants were recruited from a tertiary referral site that may include more severely ill 
Table 4 Bivariate and multivariate analysis for factors associated with time to mortality (Cox regression analysis) among children with severe acute malnutrition admitted to Mulago hospital

\begin{tabular}{|c|c|c|c|c|c|}
\hline \multirow[t]{2}{*}{ Variable } & \multirow{2}{*}{$\begin{array}{l}\text { Dead n/N } \\
\text { (\%) }\end{array}$} & Bivariate analysis & \multirow[t]{2}{*}{$p$ value } & Multivariate analysis & \multirow[t]{2}{*}{$p$ value } \\
\hline & & UHR (95\% Cl) & & AHR (95\% Cl) & \\
\hline \multicolumn{6}{|l|}{ Sex } \\
\hline Male & $38 / 160(23.8)$ & 1 & & & \\
\hline Female & 29/106 (27.4) & $1.2(0.7-1.9)$ & 0.505 & & \\
\hline \multicolumn{6}{|l|}{ Diarrhea } \\
\hline No & 24/116 (20.7) & 1 & & 1 & \\
\hline Yes & $43 / 150(28.7)$ & $1.5(0.9-2.4)$ & 0.142 & $1.1(0.7-1.9)$ & 0.684 \\
\hline \multicolumn{6}{|l|}{ Fever } \\
\hline No & 28/127 (22.1) & 1 & & & \\
\hline Yes & $39 / 139(28.1)$ & $1.3(0.8-2.1)$ & 0.339 & & \\
\hline \multicolumn{6}{|l|}{ Temperature $\left({ }^{\circ} \mathrm{C}\right)$} \\
\hline Normal & $38 / 175(21.7)$ & 1 & & & \\
\hline Hypothermia & 2/9 (22.2) & $1.02(0.2-4.2)$ & 0.977 & & \\
\hline Hyperthermia & $26 / 75(34.7)$ & $1.6(1-2.7)$ & 0.059 & & \\
\hline \multicolumn{6}{|l|}{ Dehydration } \\
\hline No & 33/168 (19.6) & 1 & & & \\
\hline Yes & $34 / 98(34.7)$ & $2(1.2-3.2)$ & 0.005 & & \\
\hline \multicolumn{6}{|l|}{ Oral thrush } \\
\hline No & 43/206 (20.9) & 1 & & & \\
\hline Yes & $24 / 60(40)$ & $2.1(1.2-3.4)$ & 0.005 & & \\
\hline \multicolumn{6}{|l|}{ Edema } \\
\hline No & 44/144 (30.6) & 1 & & 1 & \\
\hline Yes & 23/122 (18.9) & $0.6(0.4-1)$ & 0.050 & $1(0.6-1.8)$ & 0.951 \\
\hline \multicolumn{6}{|l|}{ Visible Wasting } \\
\hline No & 10/57 (17.5) & 1 & & 1 & \\
\hline Yes & $57 / 209(27.3)$ & $1.6(0.8-3.1)$ & 0.168 & $1.3(0.6-2.6)$ & 0.493 \\
\hline \multicolumn{6}{|c|}{ Signs of vitamin A deficiency } \\
\hline No & $65 / 262(24.8)$ & 1 & & 1 & \\
\hline Yes & $2 / 4(50)$ & $3.2(0.8-13.3)$ & 0.102 & $1.5(0.3-7.5)$ & 0.601 \\
\hline \multicolumn{6}{|c|}{ Diagnosis of pneumonia } \\
\hline No & $33 / 162(20.4)$ & 1 & & 1 & \\
\hline Yes & 34/104 (32.7) & $1.7(1.1-2.8)$ & 0.027 & $1.5(0.9-2.5)$ & 0.153 \\
\hline \multicolumn{6}{|l|}{ HIV status } \\
\hline Negative & $52 / 234(22.2)$ & 1 & & 1 & \\
\hline Positive & 15/32 (46.9) & $2.1(1.2-3.8)$ & 0.01 & $2.2(1.2-4.2)$ & 0.014 \\
\hline \multicolumn{6}{|l|}{ Blood culture } \\
\hline No growth & $61 / 258(23.6)$ & 1 & & 1 & \\
\hline Growth & $6 / 8(75)$ & $6.3(2.7-14.9)$ & 0.000 & $9(3.4-23.4)$ & $<0.001$ \\
\hline \multicolumn{6}{|l|}{ Glucose levels } \\
\hline$<3$ & $4 / 10(40)$ & $2.4(0.9-6.7)$ & 0.097 & $2.1(0.7-6.3)$ & 0.163 \\
\hline $3-<8.3$ & $41 / 211(19.4)$ & $2.9(1.7-4.8)$ & 0.000 & 1 & \\
\hline$\geq 8.3$ & $22 / 43(51.2)$ & & & $1.5(0.9-2.7)$ & 0.154 \\
\hline
\end{tabular}

GFR 
Table 4 Bivariate and multivariate analysis for factors associated with time to mortality (Cox regression analysis) among children with severe acute malnutrition admitted to Mulago hospital (Continued)

\begin{tabular}{|c|c|c|c|c|c|}
\hline \multirow[t]{2}{*}{ Variable } & \multirow{2}{*}{$\begin{array}{l}\text { Dead n/N } \\
\text { (\%) }\end{array}$} & Bivariate analysis & \multirow[t]{2}{*}{$p$ value } & Multivariate analysis & \multirow[t]{2}{*}{$p$ value } \\
\hline & & UHR (95\% Cl) & & AHR $(95 \% \mathrm{Cl})$ & \\
\hline$\geq 90$ & $23 / 144(16)$ & 1 & & 1 & \\
\hline $60-<90$ & $12 / 55(21.8)$ & $1.4(0.7-2.8)$ & 0.340 & $1.6(0.8-3.3)$ & 0.188 \\
\hline $30-<60$ & 19/46 (41.3) & $3.1(1.7-5.7)$ & 0.000 & $3.2(1.7-6.3)$ & 0.001 \\
\hline$<30$ & $12 / 16(75)$ & $6.5(3.2-13.1)$ & 0.000 & $5.2(2.3-11.4)$ & $<0.001$ \\
\hline \multicolumn{6}{|c|}{ Potassium (mmol/dl) } \\
\hline$\geq 3.5$ & 43/195 (22.1) & 1 & & 1 & \\
\hline$<3.5$ & 23/(34.9) & $1.7(1-2.8)$ & 0.046 & $1.3(0.8-2.3)$ & 0.336 \\
\hline \multicolumn{6}{|c|}{ Hemoglobin level (g/dl) } \\
\hline$\geq 7$ & $55 / 226(24.3)$ & 1 & & & \\
\hline$<7$ & 12/36 (33.3) & $1.3(0.7-2.5)$ & 0.351 & & \\
\hline
\end{tabular}

children than those from other facilities. On the other hand, they provide insights into management of children with SAM in hospitals with a similar set-up in other countries within sub-Saharan Africa. All laboratory tests were done once on admission and chest $\mathrm{x}$-rays were not done for a number of the participants due to lack of consent, and frequent dysfunction of the x-ray machine. The study assessed the association between admission characteristics and survival time, however these could have changed during follow-up. We cannot comment on the causes of death for these children as autopsies were not done.

\section{Conclusions}

One in four children under five years of age admitted to Mulago hospital with SAM died, which is unacceptably high. Factors associated with reduced time-to-mortality of children under five years admitted with SAM were HIV infection, bacteraemia, and eGFR below $60 \mathrm{~mL} /$ $\mathrm{min} / 1.73 \mathrm{~m}^{2}$. These children should be more closely monitored. Studies to explore the causes of reduced eGFR as well as the relationship between eGFR and mortality among children with SAM are required. Large studies to identify the causative organisms for bacteraemia and sensitivity patterns among children with SAM are also recommended to inform antibiotic treatment guidelines for children with SAM.

\footnotetext{
Abbreviations

ACU: Acute Care Unit; ART: Anti-Retroviral Therapy; CBC: Complete blood count; eGFR: Estimated Glomerular Filtration Rate; HIV: Human Immunodeficiency Virus; HEU: HIV exposed uninfected; HEl: HIV exposed infected; IRIS: Immune Reconstitution Inflammatory Syndrome; MNU: Mwanamugimu Nutrition Unit; MUAC: Mid-upper arm circumference; NGT: Nasogastric tube; PI: Principal Investigator; PIDC: Paediatric Infectious Disease Centre; PMTCT: Prevention of Mother to Child Transmission; RA: Research Assistant; SAM: Severe Acute Malnutrition; SD: Standard Deviation; TB: Tuberculosis; UNICEF: United Nations International Children's Emergency Fund; WFH: Weight for height; WHO: World Health Organisation
}

\section{Acknowledgements}

We acknowledge the department of Paediatrics and Child Health, Mulago hospital, the Makerere University Microbiology laboratory, the research assistants Robinah Asaba, Ann Kansiime, Saleh Nyende, and the children and parents/guardians who agreed to participate in the research.

\section{Authors' contributions}

All authors (VM, SK, JBK, AB, PM, JKT and DN) contributed to the design of the study, interpretation of the results, and reviewed the manuscript. DN oversaw the recruitment and follow up of study participants, and wrote the first draft of the manuscript. JBK and SK analysed the study data. All authors have read and approved the manuscript.

\section{Funding}

SURVIVAL-PLUSS project under NORHED support to Makerere University funded the study. The funder did not participate in the design of the study, collection, analysis, and interpretation of data and in writing the manuscript.

\section{Availability of data and materials}

The datasets used and/or analysed during the current study are available from the corresponding author on reasonable request.

\section{Ethics approval and consent to participate}

Permission to carry out the study was obtained from the Department of Paediatrics and Child Health of Makerere University College of Health Sciences and the School of Medicine Research and Ethics Committee (SOMREC). Written informed consent was obtained from the parent/guardian in order to participate in the study. Enrolment into the study was voluntary and caregivers had the right to withdraw from the study at any time. All test results and patient information were handled with confidentiality. Any child found HIV positive or HIV- exposed was together with the mother/caregiver referred to Baylor Uganda COE/ Mulago PIDC for initiation of ART and continuity of care.

\section{Consent for publication}

Not applicable.

\section{Competing interests}

The author(s) declare that they have no competing interests.

\section{Author details}

${ }^{1}$ Department of Paediatrics and Child Health, School of Medicine, College of Health Sciences, Makerere University, P. O. Box 7072, Kampala, Uganda. ${ }^{2}$ Research Department, Joint Clinical Research Centre, P. O. Box 10005 , Kampala, Uganda. ${ }^{3}$ Clinical Epidemiology Unit, Department of Internal Medicine, School of Medicine, College of Health Sciences, Makerere University, P. O Box 7072, Kampala, Uganda. 
Received: 13 June 2019 Accepted: 20 April 2020

Published online: 24 April 2020

\section{References}

1. Haddad L, Achadi E, Bendech MA, Ahuja A, Bhatia K, Bhutta Z, Blössner M, Borghi E, Colecraft E, de Onis M. The global nutrition report 2014: actions and accountability to accelerate the world's progress on nutrition. J Nutr. 2015;145(4):663-71.

2. WHO: Guideline: updates on the management of severe acute malnutrition in infants and children: World Health Organization; 2013.

3. UNICEF. The right ingredients: The need to invest in child nutrition. London: UNICEF UK; 2013.

4. UBOS. Uganda demographic and health survey. Kampala: Ministry of Health; 2017.

5. Bachou H, Tumwine JK, Mwadime RK, Tylleskar T. Risk factors in hospital deaths in severely malnourished children in Kampala, Uganda. BMC Pediatr. 2006;6:7.

6. Nabukeera-Barungi N, Grenov B, Lanyero B, Namusoke H, Mupere E, Christensen VB, Michaelsen KF, Mølgaard C, Rytter MJ, Friis H. Predictors of mortality among hospitalized children with severe acute malnutrition: a prospective study from Uganda. Pediatr Res. 2018;84:1.

7. Rytter MJ, Babirekere-Iriso E, Namusoke H, Christensen VB, Michaelsen KF, Ritz C, Mortensen CG, Mupere E, Friis H. Risk factors for death in children during inpatient treatment of severe acute malnutrition: a prospective cohort study. Am J Clin Nutr. 2016. https://doi.org/10.3945/ajcn.116.140822.

8. Ashworth A, Chopra M, McCoy D, Sanders D, Jackson D, Karaolis N, Sogaula $\mathrm{N}$, Schofield C. WHO guidelines for management of severe malnutrition in rural south African hospitals: effect on case fatality and the influence of operational factors. Lancet. 2004;363(9415):1110-5.

9. Fergusson $\mathrm{P}$, Tomkins A. HIV prevalence and mortality among children undergoing treatment for severe acute malnutrition in sub-Saharan Africa: a systematic review and meta-analysis. Trans R Soc Trop Med Hyg. 2009; 103(6):541-8.

10. Kerac M, Bunn J, Chagaluka G, Bahwere P, Tomkins A, Collins S, Seal A. Follow-up of post-discharge growth and mortality after treatment for severe acute malnutrition (FuSAM study): a prospective cohort study. PLoS One. 2014;9(6):e96030

11. Babirekere-lriso E, Musoke P, Kekitiinwa A. Bacteraemia in severely malnourished children in an HIV-endemic setting. Ann Trop Paediatr. 2006; 26(4):319-28.

12. Irena AH, Mwambazi M, Mulenga V. Diarrhea is a major killer of children with severe acute malnutrition admitted to inpatient set-up in Lusaka, Zambia. Nutr J. 2011;10(1):110.

13. Health Mo: Guidelines for integrated Manangement of acute malnutrition in Uganda in. Kampala 2016.

14. Group WMGRS. WHO Child Growth Standards based on length/height, weight and age. Acta paediatrica Supplement. 2006;450:76.

15. Schwartz G, Haycock G, Edelmann C, Spitzer A. A simple estimate of glomerular filtration rate in children derived from body length and plasma creatinine. Pediatrics. 1976:58(2):259-63.

16. Kambale R, Kasengi J, Kivukuto J, Cubaka L, Mungo B, Balaluka G. Infectious profile and mortality of children aged 0-5 years admitted with severe acute malnutrition: a retrospective cohort study conducted in the therapeutic nutritional Center in Bukavu, republic of Congo. Pan African Med J. 2015;23: 139.

17. Kanan SO, Swar MO. Prevalence and outcome of severe malnutrition in children less than five-year-old in Omdurman Paediatric hospital, Sudan. Sudanese J Paediatrics. 2016;16(1):23.

18. Attia S, Versloot CJ, Voskuijl W, van Vliet SJ, Di Giovanni V, Zhang L, Richardson S, Bourdon C, Netea MG, Berkley JA. Mortality in children with complicated severe acute malnutrition is related to intestinal and systemic inflammation: an observational cohort study. Am J Clin Nutr. 2016;104(5): $1441-9$.

19. English L, Kumbakumba E, Larson CP, Kabakyenga J, Singer J, Kissoon N, Ansermino JM, Wong H, Kiwanuka J, Wien M. Pediatric out-of-hospital deaths following hospital discharge: a mixed-methods study. Afr Health Sci. 2016;16(4):883-91.

20. Bachou H, Tumwine JK, Mwadime RK, Ahmed T, Tylleskar T. Reduction of unnecessary transfusion and intravenous fluids in severely malnourished children is not enough to reduce mortality. Ann Trop Paediatr. 2008;28(1): 23-33.
21. Jarso H, Workicho A, Alemseged F. Survival status and predictors of mortality in severely malnourished children admitted to Jimma University specialized hospital from 2010 to 2012, Jimma, Ethiopia: a retrospective longitudinal study. BMC Pediatr. 2015;15(1):76.

22. Chinkhumba J, Tomkins A, Banda T, Mkangama C, Fergusson P. The impact of HIV on mortality during in-patient rehabilitation of severely malnourished children in Malawi. Trans R Soc Trop Med Hyg. 2008;102(7):639-44.

23. Freemark M. Metabolomics in nutrition research: biomarkers predicting mortality in children with severe acute malnutrition. Food Nutr Bull. 2015; 36(1 Suppl):S88-92..

24. Nyeko R, Calbi V, Sseguija BO, Ayot GF. Treatment outcome among children under-five years hospitalized with severe acute malnutrition in St. Mary's hospital Lacor, Northern Uganda. BMC Nutrition. 2016;2(1):19.

25. Marquez C, Okiring J, Chamie G, Ruel TD, Achan J, Kakuru A, Kamya MR, Charlebois ED, Havlir DV, Dorsey G. Increased morbidity in early childhood among HIV-exposed uninfected children in Uganda is associated with breastfeeding duration. J Trop Pediatr. 2014;60(6):434-41.

26. Rytter MJH, Kolte L, Briend A, Friis H, Christensen VB. The immune system in children with malnutrition—a systematic review. PLoS One. 2014;9(8): e105017.

27. Abrha A, Abdissa A, Beyene G, Getahun G, Girma T. Bacteraemia among severely malnourished children in jimma university hospital, ethiopia. Ethiop J Health Sci. 2011;21(3):175-82.

28. Chisti MJ, Salam MA, Bardhan PK, Faruque AS, Shahid AS, Shahunja KM, Das SK, Hossain Ml, Ahmed T. Treatment failure and mortality amongst children with severe acute malnutrition presenting with cough or respiratory difficulty and radiological pneumonia. PLoS One. 2015;10(10):e0140327.

29. Idris UA, Robinson WD, Faruk JA, Gwarzo GD. Prevalence of bacteremia among febrile children with severe malnutrition in North Western Nigeria. Nigerian J Gen Pract. 2018;16(1):25.

30. Morgan DJ, Okeke IN, Laxminarayan R, Perencevich EN, Weisenberg S. Nonprescription antimicrobial use worldwide: a systematic review. Lancet Infect Dis. 2011;11(9):692-701.

31. Bachou H, Tylleskär T, Kaddu-Mulindwa DH, Tumwine JK. Bacteraemia among severely malnourished children infected and uninfected with the human immunodeficiency virus-1 in Kampala, Uganda. BMC Infect Dis. 2006; 6(1):1.

32. Conroy AL, Hawkes M, Elphinstone RE, Morgan C, Hermann L, Barker KR, Namasopo S, Opoka RO, John CC, Liles WC. Acute kidney injury is common in pediatric severe malaria and is associated with increased mortality. In: Open forum infectious diseases: 2016: Oxford University Press; 2016. p. ofw046.

33. Alkandari $\mathrm{O}$, Eddington KA, Hyder A, Gauvin F, Ducruet $T$, Gottesman R, Phan V, Zappitelli M. Acute kidney injury is an independent risk factor for pediatric intensive care unit mortality, longer length of stay and prolonged mechanical ventilation in critically ill children: a two-center retrospective cohort study. Crit Care. 2011;15(3):R146.

\section{Publisher's Note}

Springer Nature remains neutral with regard to jurisdictional claims in published maps and institutional affiliations.

Ready to submit your research? Choose BMC and benefit from:

- fast, convenient online submission

- thorough peer review by experienced researchers in your field

- rapid publication on acceptance

- support for research data, including large and complex data types

- gold Open Access which fosters wider collaboration and increased citations

- maximum visibility for your research: over $100 \mathrm{M}$ website views per year

At BMC, research is always in progress.

Learn more biomedcentral.com/submissions 